\title{
Findings from What We Eat in America, National Health and Nutrition Examination Survey 2011-2014 support salad consumption as an effective strategy for improving adherence to dietary recommendations
}

\author{
Rhonda S Sebastian*, Cecilia Wilkinson Enns, Joseph D Goldman, M Katherine Hoy and \\ Alanna J Moshfegh \\ US Department of Agriculture, Agricultural Research Service, Beltsville Human Nutrition Research Center, Food \\ Surveys Research Group, BARC-West - Building 005 - Room 102, Beltsville, MD 20705-2350, USA
}

Submitted 11 May 2018: Final revision received 21 September 2018: Accepted 19 November 2018: First published online 15 February 2019

\begin{abstract}
Objective: To verify the previously untested assumption that eating more salad enhances vegetable intake and determine if salad consumption is in fact associated with higher vegetable intake and greater adherence to the Dietary Guidelines for Americans (DGA) recommendations.

Design: Individuals were classified as salad reporters or non-reporters based upon whether they consumed a salad composed primarily of raw vegetables on the intake day. Regression analyses were applied to calculate adjusted estimates of food group intakes and assess the likelihood of meeting Healthy US-Style Food Pattern recommendations by salad reporting status.

Setting: Cross-sectional analysis of data collected in 2011-2014 in What We Eat in America, the dietary intake component of the National Health and Nutrition Examination Survey.

Participants: US adults ( $n$ 9678) aged $\geq 20$ years (excluding pregnant and lactating women).

Results: On the intake day, $23 \%$ of adults ate salad. The proportion of individuals reporting salad varied by sex, age, race, income, education and smoking status $(P<0.001)$. Compared with non-reporters, salad reporters consumed significantly larger quantities of vegetables (total, dark green, red/orange and other), which translated into a two- to threefold greater likelihood of meeting recommendations for these food groups. More modest associations were observed between salad consumption and differences in intake and likelihood of meeting recommendations for protein foods (total and seafood), oils and refined grains.

Conclusions: Study results confirm the DGA message that incorporating more salads in the diet is one effective strategy (among others, such as eating more cooked vegetables) to augment vegetable consumption and adherence to dietary recommendations concerning vegetables.
\end{abstract}

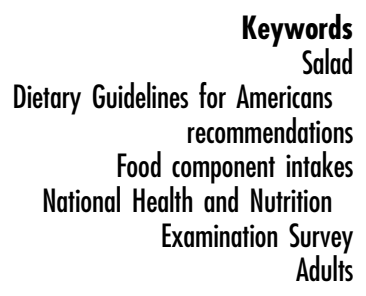

Intake of vegetables is associated with reduced risk of such chronic diseases and conditions as cancer ${ }^{(1-4)}$, diabetes $^{(5)}, \mathrm{CVD}^{(4,5)}$, hypertension ${ }^{(6)}$ and stroke ${ }^{(7)}$. There is some evidence that inverse associations with these conditions are stronger for raw vegetables than for their cooked counterparts ${ }^{(1,2,5,7)}$. These benefits and others may be related to the fact that vegetables are a source of many nutrients that tend to be low in the typical American diet, including dietary fibre, vitamins A (present in vegetables as provitamin A carotenoids), $\mathrm{C}$ and $\mathrm{E}$, choline, $\mathrm{Mg}$ and $\mathrm{K}$.
Vegetables are also a rich source of polyphenolic compounds (e.g. flavonoids) with demonstrated antioxidant and anti-inflammatory activity ${ }^{(8)}$.

For more than a century, the US Department of Agriculture (USDA) has published various food guides instructing consumers about choosing foods from specified food groups, including vegetables, in order to optimise nutrient intakes ${ }^{(9)}$. Since the 1980s, US Federal dietary guidance has been conveyed to the public through the Dietary Guidelines for Americans (DGA), published 
jointly by the USDA and the US Department of Health and Human Services every 5 years. The most recent version, the DGA 2015-2020, includes USDA Food Patterns specifying the number of servings of vegetables and other food groups that individuals should consume based on their age, sex and activity level ${ }^{(10)}$. Because different types of vegetables contain different nutrients, the Food Patterns promote variety by including recommendations for five vegetable subgroups: dark green, red and orange, legumes, starchy and 'other' vegetables (i.e. vegetables not included in the other subgroups).

Although vegetable intake is emphasised in the DGA and other nationwide programmes promoting good nutrition ${ }^{(11-17)}$, most individuals in the USA consume far less than recommended. Mean usual intake of total vegetables by men in 2007-2010 was 1.8 cup equivalents, whereas their recommended levels ranged from 2.5 to 4 cup equivalents ${ }^{(10,18)}$. For women, mean usual total vegetables intake was 1.6 cup equivalents, and their range of recommended levels was 2 to 3 cup equivalents. Only $11 \%$ of men and $13 \%$ of women had intakes meeting their total vegetables recommendation. There was some variation by age and sex, but the highest percentage of adults meeting their total vegetables recommendation was only $33 \%$ (among women aged 51-70 years). The percentage of adults meeting recommendations for the vegetable subgroups is also poor, although somewhat less extreme for 'other' vegetables than for the other subgroups. Workable strategies are needed to address this disconnect between intake and recommendations.

Inclusion of vegetable dishes, such as salads, in most meals and snacks is one of the consumer strategies proposed in the DGA with a view to boosting vegetable consumption $^{(10)}$. Since salads often contain multiple vegetables, it has been assumed that incorporating them into one's diet would improve not only total vegetable intake but also intakes of various vegetable subgroups. However, whether or not this is true remains untested. The sparse literature about nationwide salad consumption by US adults is either dated and limited to a restricted age range of the adult population ${ }^{(19)}$ or confined to descriptive estimates $^{(20)}$. No study to date has analysed whether salad consumption is associated with higher likelihood of meeting US national eating pattern recommendations.

It is possible that in actual practice salad might be consumed in place of other vegetable dishes, which would yield no net improvement in vegetable intake or the percentage of the population meeting vegetable recommendations. A thorough evaluation of the implications of this strategy with regard to total dietary intake and DGA adherence is warranted.

Thus, the objective of the present study was to determine if salad consumption is associated with higher vegetable intake and greater adherence to recommendations outlined in the DGA 2015-2020. Specifically, the study analysed whether intakes of USDA Food Pattern components and adherence to Healthy US-Style Eating Pattern recommendations differed between those who reported a salad on the intake day (reporters) and those who did not (non-reporters) in a nationally representative sample of US adults.

\section{Methods}

\section{Sample}

Data used in the present study were collected between 2011 and 2014 in What We Eat in America (WWEIA), the dietary intake component of the National Health and Nutrition Examination Survey (NHANES) ${ }^{(21)}$. The NHANES sample was designed to be representative of the civilian, non-institutionalised US population ${ }^{(22)}$. A complex, multistage, area probability sample design was used to select persons within households.

The examination response rate among adults aged $\geq 20$ years was $64.5 \%$ in $2011-2012$ and $63.7 \%$ in $2013-2014^{(23)}$. A total of 9848 adults aged $\geq 20$ years (90.3\% of examined survey participants in this age group) provided one day of complete dietary intake data. Pregnant and lactating women ( $n$ 170) were excluded, yielding a final analytic sample of 9678 adults (4808 males and 4870 females).

\section{Identification of salads}

WWEIA day 1 dietary data were collected in person by trained interviewers fluent in English and Spanish using the USDA Automated Multiple-Pass Method for the $24 \mathrm{~h}$ recall. This method is a five-step multiple-pass approach designed to enhance complete and accurate food recall and reduce respondent burden ${ }^{(24,25)}$. WWWEIA 2011-2012 and WWEIA 2013-2014 dietary intake data files, documentation and related survey materials are available online ${ }^{(26,27)}$.

Unlike some food terms whose definitions are uncontroversial (e.g. apple, potato, oatmeal), the term 'salad' has no single, universally accepted meaning. On the contrary, common foods with the word 'salad' in their name are exceedingly diverse in their ingredients and methods of preparation, such as garden salad, Caesar salad, taco salad, cabbage salad (coleslaw), chicken salad, tuna salad, macaroni/pasta salad, fruit salad and potato salad.

For the purposes of the present study, a salad was considered to be composed primarily of raw vegetables. Foods that are botanically fruits yet are treated as vegetables in culinary usage were considered vegetables, including tomatoes, cucumbers and avocados. The following were considered salads:

1. raw lettuce or other leafy greens consumed with one or more other raw vegetables and/or with one or more common non-vegetable salad ingredients (such as dressing, croutons or sunflower seeds); 
2. a mixture of two or more raw vegetables other than lettuce/greens (with or without dressing);

3. a single raw vegetable other than lettuce/greens with dressing; and

4. raw lettuce/greens consumed alone.

Thus, foods that had 'salad' in their name but did not have raw vegetables as their predominant ingredient(s) were excluded. Also, raw lettuce/greens consumed as part of a sandwich or in a mixed food that did not meet any of the preceding criteria was excluded.

As evident from the inclusion criteria, no specific ingredient was required to satisfy the salad definition. However, the majority of salads (78\%) consumed by adults in 2011-2014 contained lettuce or another leafy green, and a similarly high percentage (86\%) included a dressing.

All foods and beverages reported in WWEIA are coded using one or more USDA food codes for the purpose of assigning a nutrient profile. Although there are a number of food codes that represent raw vegetable-based salads, only a small percentage of the salads reported in 2011-2014 were coded with a single food code. Most salads reported $(87 \%)$ were coded using several food codes. For example, six food codes were used in coding a salad containing lettuce, cabbage, carrots, chicken, black beans and honey mustard dressing. In the dietary data files, foods that have been coded using more than one food code can be identified through the presence of linking variables ${ }^{(28,29)}$.

Individuals who ate any amount of an item classified as salad on the intake day were considered to be salad 'reporters', whereas individuals who did not eat any salad were considered 'non-reporters'.

\section{Assignment of food group recommendations}

The USDA Food Patterns are three distinct eating patterns from which consumers can choose: Healthy US-Style, Healthy Mediterranean-Style and Healthy Vegetarian. For each of twelve energy levels, each pattern specifies recommended amounts to consume from five food groups (vegetables, fruits, grains, dairy, protein foods), their subgroups and oils ${ }^{(10)}$. None of the recommendations for total vegetables or any of the vegetable subgroups differ between the US-Style and Mediterranean-Style eating patterns. Recommended amounts of the vegetable subgroup legumes (beans and peas) are considerably higher in the Vegetarian pattern than in the US-Style pattern. Since earlier research has shown that few adults meet even the lower recommendations for legumes ${ }^{(18)}$, the present study assessed adherence only to the US-Style pattern.

The Food Patterns also set limits on intake of 'calories for other uses', which are derived from added sugars, added refined starches, solid fats, alcohol and amounts of food consumed from any food group that exceed the recommendation for that group ${ }^{(10)}$. The Food Patterns are based on foods in their most nutrient-dense forms, i.e. lean or low-fat and prepared without added fats or sugars. When foods consumed are not in the most nutrient-dense form, the resulting excess energy is tallied as 'calories for other uses'. For example, plain non-fat yoghurt is more nutrient-dense than fruit-flavoured whole milk yogurt. Energy from the solid fats and added sugars in the latter product is counted as 'calories for other uses'. In addition to the overall limits on 'calories for other uses', the DGA include recommendations to limit added sugars and solid fats each to less than $10 \%$ of energy and alcohol to $\leq 1$ $\mathrm{drink} / \mathrm{d}$ for women and $\leq 2 \mathrm{drinks} / \mathrm{d}$ for men.

In order to evaluate adherence to DGA recommendations, the foods in the WWEIA intake data files are converted into the amounts of Food Pattern components present in them by applying values from the USDA Food Patterns Equivalents Database (FPED) ${ }^{(30-32)}$. Data files containing total aggregate daily amounts of Food Pattern components consumed by each respondent in WWEIA, NHANES 2011-2012 and 2013-2014 are available online, as are the corresponding versions of the FPED ${ }^{(33)}$.

The FPED provides values for thirty-seven components included in the USDA Food Patterns. Although the FPED does not contain a variable for 'calories for other uses' overall, it does contain added sugars (teaspoons), solid fats (grams) and alcoholic drinks (number). FPED amounts of added sugars and solid fats were converted to calories (i.e. kilocalories; $1 \mathrm{kcal}=4.184 \mathrm{~kJ}$ ) as follows: added sugars in teaspoons was multiplied by $4.2 \mathrm{~g} /$ teaspoon and then by $4 \mathrm{kcal} / \mathrm{g}$; solid fats in grams was multiplied by $9 \mathrm{kcal} / \mathrm{g}$.

Each individual's USDA Food Pattern energy level and corresponding food group recommendations are determined based on sex, age and activity level ${ }^{(10)}$. In the present study, activity level was estimated using NHANES Physical Activity Questionnaire data ${ }^{(34,35)}$. Minutes of physical activity per week were based on the respondent's estimate of time spent in work, recreational and transportrelated activity in a typical week. Minutes spent in 'vigorous' activity were multiplied by $2^{(36)}$. Individuals whose total activity summed to less than $150 \mathrm{~min} /$ week were considered sedentary; 150-299 min/week, moderately active; and $\geq 300 \mathrm{~min} /$ week, active.

Among men, the summative total of self-reported time spent in work, recreational and transport-related physical activity resulted in $29 \%$ being classified as sedentary, 9\% as moderately active and $61 \%$ as active. Consequently, the energy levels assigned to men in the present study were the following: $2000 \mathrm{kcal}(8368 \mathrm{~kJ} ; 10 \%$ of men), $2200 \mathrm{kcal}$ (9205kJ; 13\%), $2400 \mathrm{kcal}(10042 \mathrm{~kJ} ; 13 \%), 2600 \mathrm{kcal}$ $(10878 \mathrm{~kJ} ; \quad 17 \%), \quad 2800 \mathrm{kcal} \quad(11715 \mathrm{~kJ} ; 24 \%)$ and $3000 \mathrm{kcal}(12552 \mathrm{~kJ} ; 23 \%)$. Among women, 44\% were classified as sedentary, $12 \%$ as moderately active and $45 \%$ as active, and the energy levels assigned were $1600 \mathrm{kcal}$ $(6694 \mathrm{~kJ} ; 24 \%$ of women), $1800 \mathrm{kcal}(7531 \mathrm{~kJ} ; 22 \%)$, $2000 \mathrm{kcal}(8368 \mathrm{~kJ} ; 18 \%), 2200 \mathrm{kcal}(9205 \mathrm{~kJ} ; 26 \%)$ and $2400 \mathrm{kcal}(10042 \mathrm{~kJ} ; 11 \%)$. 


\section{Statistical analysis}

Analyses were performed using the statistical software package SAS $^{\circledR}{ }^{\circledR}$ callable SUDAAN ${ }^{\circledR}$, release $11 \cdot 0$ (2012; RTI International, Research Triangle Park, NC, USA). SUDAAN increases the validity of inferred results, as the variance estimates generated are corrected to account for the multistage stratified cluster probability design of the NHANES survey ${ }^{(37,38)}$. Survey weights designed to account for unequal probability of selection, non-coverage and non-response were applied in all analyses to produce estimates representative of the US population.

Descriptive analyses utilizing $\chi^{2}$ goodness-of-fit tests were conducted to determine whether the distribution of salad reporting status differed by demographic, anthropometric and lifestyle characteristics.

Linear regression analyses were conducted to provide mean intake estimates of Food Pattern components by salad reporting status. Characteristics included as adjustment variables in these analyses were sex, race/ethnicity (non-Hispanic White, non-Hispanic Black, non-Hispanic Asian, Hispanic, other race), age, income status (as poverty income ratio or PIR, which is the ratio of family income to poverty expressed as a percentage ${ }^{(39)}$ ) and smoking status (never, former, current). $t$ tests were conducted to identify significant differences in intake between salad reporters and non-reporters for each food component in the Healthy US-Style Eating Pattern.

Logistic regression was used to estimate the percentage of adults with intakes meeting their Healthy US-Style Eating Pattern recommendations and to determine the likelihood of salad reporters meeting each recommendation relative to non-reporters, with adjustment for the same variables as in the linear regression analyses. These model-adjusted prevalence estimates and risk ratios were calculated using the average marginal prediction approach described by Graubard and $\mathrm{Korn}^{(40)}$ and Bieler et al. ${ }^{(41)}$. This approach is designed to permit unbiassed comparisons of risk between population subgroups after controlling for differences in their covariate distributions. Since the Food Pattern recommendations for vegetable and protein food subgroups are specified on a weekly rather than a daily basis, one-seventh of an individual's recommendation was used as the criterion for meeting that recommendation.

Since earlier research indicated that salad reporting status differed significantly by sex ${ }^{(20)}$, analyses comparing food component intakes and percentages meeting each Food Pattern recommendation were conducted for all adults collectively and for men and women separately.

A level of $P<0.001$ was applied in all analyses to determine statistical significance.

\section{Results}

\section{Salad reporting status by characteristics}

On the intake day, $23 \%$ of adults ate salad (Table 1). Among salad reporters, the majority (89\%) consumed only one item classified as salad, whereas $11 \%$ ate more than one such item (data not shown).

The percentage of individuals reporting salad varied by all of the demographic and most of the lifestyle characteristics studied $(P<0.001$; Table 1$)$. Reporting salad appeared to be more common among women, those aged 40 years or over, non-Hispanic Whites, higher-income individuals, those with education beyond high school, and never and former smokers. In contrast, the percentage of individuals reporting salad did not vary by BMI, waist circumference or minutes of physical activity per week.

\section{Contribution of salad to reporters' vegetable intakes}

Salads' contributions to overall intakes of vegetable components among those who reported salad on the intake day are shown in Fig. 1. Among male and female salad reporters analysed together, salad made substantial contributions to intakes of total (51.9\%), dark green $(76.7 \%)$, red and orange (46.1\%) and 'other' vegetables (67.6\%), and much smaller contributions to their intakes of legumes $(11.9 \%)$ and starchy vegetables $(2 \cdot 7 \%)$. Contributions by salad to intakes of these food groups did not differ by sex $(P>0 \cdot 001)$

\section{Food Pattern component intakes}

Intakes of USDA Food Pattern components in the Healthy US-Style Eating Pattern are shown in Table 2. Among all adults (i.e. males and females analysed together), salad reporters had significantly higher intakes of total, dark green, red and orange, and 'other' vegetables than did non-reporters $(P<0 \cdot 001)$. The mean intake of total vegetables by salad reporters (2.64 cup equivalents) was $86 \%$ higher than that of non-reporters (1.42 cup equivalents). Similarly, salad reporters had considerably higher intakes of dark green $(+280 \%)$, red and orange $(+79 \%)$ and 'other' vegetables $(+167 \%)$ than did non-reporters. Intakes of legumes (beans and peas) and starchy vegetables did not differ by salad reporting status.

Intakes from several non-vegetable Food Pattern components also differed significantly between salad reporters and non-reporters. Salad reporters had lower intakes of total grains and refined grains than did non-reporters. Intakes of total protein foods and seafood were higher among salad reporters than non-reporters, although it should be noted that seafood intake was low regardless of salad reporting status. Salad reporters also had a higher intake of oils than did non-reporters (34.6 v. 24.4 g). Whereas intakes of solid fats (in grams) and added sugars (in teaspoon equivalents) did not differ between salad reporters and non-reporters, the percentages of total energy intake that were attributable to these components were significantly lower among salad reporters than nonreporters. Intake of the following USDA Food Pattern components did not differ by salad reporting status: fruits; 
Table 1 Salad reporting status by selected characteristics; US adults ( $n$ 9678) aged $\geq 20$ years, What We Eat in America, National Health and Nutrition Examination Survey 2011-2014

\begin{tabular}{|c|c|c|c|c|}
\hline \multirow[b]{2}{*}{ Characteristic } & \multirow[b]{2}{*}{$n^{*}$} & \multicolumn{2}{|c|}{ Salad reporting status } & \multirow[b]{2}{*}{$P \dagger$} \\
\hline & & Non-reporters & Reporters & \\
\hline All individuals & 9678 & $77 \cdot 0$ & $23 \cdot 0$ & - \\
\hline \multicolumn{5}{|l|}{ Demographic } \\
\hline $\operatorname{Sex}(\%)$ & & & & $<0.001$ \\
\hline Male & 4808 & $80 \cdot 8$ & $19 \cdot 2$ & \\
\hline Femaleł & 4870 & $73 \cdot 3$ & $26 \cdot 7$ & \\
\hline Age group (\%) & & & & $<0.001$ \\
\hline $20-39$ years & 3301 & $82 \cdot 4$ & $17 \cdot 6$ & \\
\hline 40-59 years & 3309 & $75 \cdot 0$ & $25 \cdot 0$ & \\
\hline$\geq 60$ years & 3068 & $72 \cdot 8$ & $27 \cdot 2$ & \\
\hline Race/ethnicity (\%) & & & & $<0.001$ \\
\hline Non-Hispanic White & 4007 & $73 \cdot 6$ & $26 \cdot 4$ & \\
\hline Non-Hispanic Black & 2243 & $86 \cdot 7$ & $13 \cdot 3$ & \\
\hline Non-Hispanic Asian & 1110 & $81 \cdot 4$ & 18.6 & \\
\hline Hispanic & 2029 & $81 \cdot 8$ & $18 \cdot 2$ & \\
\hline Other§ & 289 & $86 \cdot 2$ & $13 \cdot 8$ & \\
\hline Income as PIR $\|(\%)$ & & & & $<0.001$ \\
\hline $0-130$ & 3111 & 84.7 & $15 \cdot 3$ & \\
\hline $131-350$ & 3082 & $78 \cdot 3$ & $21 \cdot 7$ & \\
\hline$>350$ & 2765 & $71 \cdot 0$ & $29 \cdot 0$ & \\
\hline Not reported & 720 & 78.5 & 21.5 & \\
\hline Educational levelף (\%) & & & & $<0.001$ \\
\hline$<$ High school graduate & 2104 & 85.4 & 14.6 & \\
\hline High school graduate & 2123 & 81.4 & $18 \cdot 6$ & \\
\hline$>$ High school graduate & 5451 & 73.5 & 26.5 & \\
\hline \multicolumn{5}{|l|}{ Anthropometric } \\
\hline BMI category (\%) & & & & 0.035 \\
\hline$<25.0 \mathrm{~kg} / \mathrm{m}^{2}$ & 2920 & $75 \cdot 6$ & $24 \cdot 4$ & \\
\hline $25 \cdot 0-29 \cdot 9 \mathrm{~kg} / \mathrm{m}^{2}$ & 3073 & $75 \cdot 5$ & 24.5 & \\
\hline$\geq 30.0 \mathrm{~kg} / \mathrm{m}^{2}$ & 3588 & $79 \cdot 3$ & $20 \cdot 7$ & \\
\hline Waist circumference (\%) & & & & 0.897 \\
\hline At or below cut-off ${ }^{\star \star}$ & 5154 & $76 \cdot 8$ & 23.2 & \\
\hline Above cut-off ${ }^{\star \star}$ & 4157 & $77 \cdot 0$ & 23.0 & \\
\hline \multicolumn{5}{|l|}{ Lifestyle } \\
\hline Activity status $\dagger \dagger(\%)$ & & & & 0.242 \\
\hline$<150 \mathrm{~min} /$ week & 3836 & 78.4 & $21 \cdot 6$ & \\
\hline 150-299 min/week & 1094 & $74 \cdot 4$ & $25 \cdot 6$ & \\
\hline$\geq 300 \mathrm{~min} /$ week & 4748 & $76 \cdot 6$ & $23 \cdot 4$ & \\
\hline 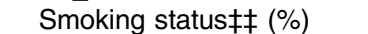 & & & & $<0.001$ \\
\hline Never smoker & 5429 & $75 \cdot 7$ & $24 \cdot 3$ & \\
\hline Former smoker & 2260 & $72 \cdot 6$ & $27 \cdot 4$ & \\
\hline Current smoker & 1983 & 85.9 & $14 \cdot 1$ & \\
\hline
\end{tabular}

*Within each characteristic, counts do not necessarily sum to the count of all individuals due to missing data. †The $x^{2}$ test was used to identify relationships between salad reporting and characteristics.

†Excludes pregnant and lactating females.

SIncludes both individuals who were of races other than those listed and those who were multiracial.

IIPIR (poverty income ratio) is the ratio of family income to poverty, expressed as a percentage ${ }^{(39)}$.

†Educational level equals highest level of school completed. 'High school graduate' includes general equivalency diploma (GED) or equivalent.

**National Institutes of Health/National Heart, Lung, and Blood Institute cut-offs used in assessing risk for type 2 diabetes, hypertension and CVD are $102 \mathrm{~cm}$ for men and $88 \mathrm{~cm}$ for women ${ }^{(55)}$.

††Includes all physical activity, regardless of purpose (recreation, in the performance of work or as a means of transportation), with each vigorous-intensity minute counted as the equivalent of 2 moderate-intensity minutes $^{(36)}$.

¥¥Participants who reported smoking $<100$ cigarettes in their lives were classified as 'never smokers', those who had smoked $\geq 100$ cigarettes but did not smoke at all at the time of the survey were classified as 'former smokers', and those who smoked cigarettes every day or some days at the time of the survey were classified as 'current smokers'.

total grains; whole grains; dairy; meats, poultry, eggs; nuts, seeds, soya products; and alcoholic drinks.

For men and women analysed separately, the pattern of significant differences mostly reflected that seen for all adults. However, no significant differences by salad reporting status were seen for either sex in intake of total grains and the percentage of total energy intake from added sugars; for men in intakes of total protein foods and seafood; and for women in intake of refined grains.

\section{Adberence to Healthy US-Style Eating Pattern recommendations}

As shown in Table 3, among all adults, the percentage of individuals meeting their total vegetable recommendation 


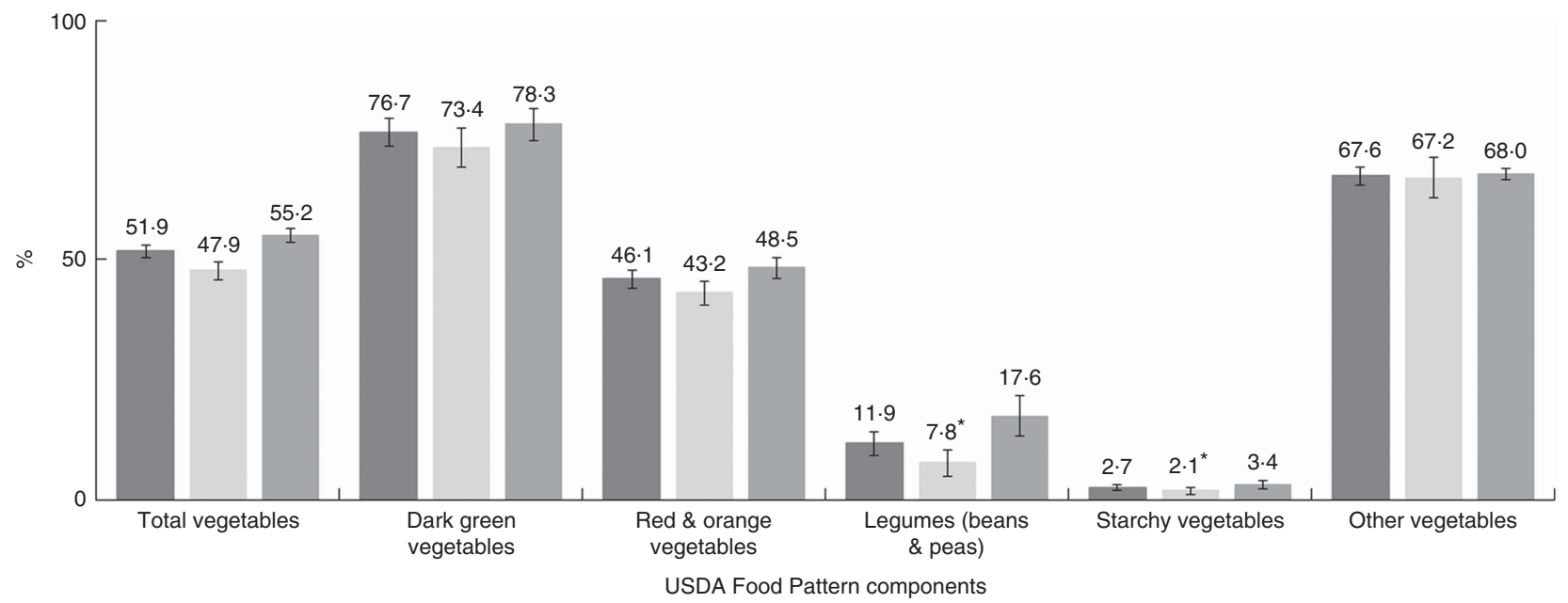

Fig. 1 Contributions by salads to salad reporters' total daily intakes of US Department of Agriculture (USDA) Food Pattern vegetable components, overall and by sex ( $\square$, males and femalest; $\square$, males; $\square$, females $\uparrow$ ); US adults ( $n$ 9678) aged $\geq 20$ years, What We Eat in America, National Health and Nutrition Examination Survey 2011-2014. Values are means, with their standard errors represented by vertical bars. *Estimate is less precise than others due to small sample size and/or relatively large standard error. †Excludes pregnant and lactating females

Table 2 Intakes* of US Department of Agriculture (USDA) Food Pattern components specified in the Healthy US-Style Eating Pattern†, by salad reporting status, overall and by sex; US adults $(n$ 9678) aged $\geq 20$ years, What We Eat in America, National Health and Nutrition Examination Survey 2011-2014

\begin{tabular}{|c|c|c|c|c|c|c|c|c|c|c|c|c|}
\hline \multirow[b]{4}{*}{ USDA Food Pattern component (unit) } & \multicolumn{12}{|c|}{ Salad reporting status, by sex } \\
\hline & \multicolumn{4}{|c|}{ Males and females $\ddagger$} & \multicolumn{4}{|c|}{ Males } & \multicolumn{4}{|c|}{ Females $\ddagger$} \\
\hline & \multicolumn{2}{|c|}{$\begin{array}{l}\text { Non-reporters } \\
\quad(n \text { 7802) }\end{array}$} & \multicolumn{2}{|c|}{$\begin{array}{l}\text { Reporters } \\
(n 1876)\end{array}$} & \multicolumn{2}{|c|}{$\begin{array}{l}\text { Non-reporters } \\
\quad(n \text { 4022) }\end{array}$} & \multicolumn{2}{|c|}{$\begin{array}{l}\text { Reporters } \\
\text { (n 786) }\end{array}$} & \multicolumn{2}{|c|}{$\begin{array}{l}\text { Non-reporters } \\
\quad(n 3780)\end{array}$} & \multicolumn{2}{|c|}{$\begin{array}{l}\text { Reporters } \\
(n \text { 1090) }\end{array}$} \\
\hline & Mean & SE & Mean & SE & Mean & SE & Mean & SE & Mean & SE & Mean & SE \\
\hline Vegetables§ (c-eq.) & 1.42 & 0.02 & $2 \cdot 64 \rrbracket$ & 0.06 & 1.60 & 0.04 & $2 \cdot 88 \rrbracket$ & $0 \cdot 10$ & $1 \cdot 24$ & 0.02 & $2 \cdot 429$ & 0.05 \\
\hline Dark green vegetables & $0 \cdot 10$ & 0.01 & $0.38 \pi$ & 0.02 & $0 \cdot 10$ & 0.01 & $0.30 \pi$ & 0.02 & $0 \cdot 10$ & 0.01 & $0.44 \pi$ & 0.03 \\
\hline Red \& orange vegetables & 0.34 & 0.01 & $0.61 \rrbracket$ & 0.02 & 0.39 & 0.01 & $0.65 \pi$ & 0.03 & 0.30 & 0.01 & $0.56 ף$ & 0.02 \\
\hline Legumes (beans \& peas) & 0.12 & $<0.01$ & 0.14 & 0.01 & 0.15 & 0.01 & 0.19 & 0.02 & 0.09 & 0.01 & 0.10 & 0.01 \\
\hline Starchy vegetables & 0.44 & 0.01 & 0.39 & 0.02 & 0.51 & 0.02 & 0.47 & 0.04 & 0.37 & 0.01 & 0.32 & 0.02 \\
\hline Other vegetables & 0.42 & 0.01 & $1 \cdot 12 \mathbb{1}$ & 0.03 & 0.45 & 0.01 & $1 \cdot 27 \pi$ & 0.06 & 0.38 & 0.01 & $1.00 \pi$ & 0.03 \\
\hline Fruits (c-eq.) & 0.90 & 0.02 & 1.06 & 0.05 & 0.92 & 0.03 & $1 \cdot 11$ & 0.07 & 0.88 & 0.03 & 1.02 & 0.06 \\
\hline Grains (oz-eq.) & $6 \cdot 79$ & 0.06 & $6 \cdot 31 \rrbracket$ & 0.11 & $7 \cdot 78$ & $0 \cdot 10$ & 7.06 & $0 \cdot 18$ & $5 \cdot 82$ & 0.07 & $5 \cdot 51$ & 0.14 \\
\hline Whole grains & 0.91 & 0.03 & 1.01 & 0.05 & 0.98 & 0.04 & $1 \cdot 14$ & 0.08 & 0.85 & 0.02 & 0.90 & 0.05 \\
\hline Refined grains & $5 \cdot 88$ & 0.06 & $5 \cdot 30 \pi$ & 0.11 & $6 \cdot 80$ & $0 \cdot 10$ & $5.93 \pi$ & 0.19 & 4.97 & 0.07 & 4.61 & 0.13 \\
\hline Dairy (c-eq.) & 1.64 & 0.03 & 1.61 & 0.04 & 1.87 & 0.04 & 1.85 & 0.08 & 1.41 & 0.03 & 1.37 & 0.05 \\
\hline Protein foods§ (oz-eq.) & $6 \cdot 14$ & 0.06 & $6 \cdot 62 \rrbracket$ & $0 \cdot 11$ & 7.50 & 0.11 & 7.87 & 0.18 & 4.82 & 0.08 & $5 \cdot 34 \uparrow$ & 0.12 \\
\hline Seafood & 0.61 & 0.05 & $0.82 ף$ & 0.06 & 0.70 & 0.07 & 0.90 & 0.09 & 0.53 & 0.05 & $0.74 \rrbracket$ & 0.07 \\
\hline Meats, poultry, eggs & 4.69 & 0.06 & 4.78 & 0.14 & $5 \cdot 86$ & 0.09 & 5.80 & 0.22 & 3.55 & 0.07 & 3.74 & 0.12 \\
\hline Nuts, seeds, soya products & 0.84 & 0.04 & 1.01 & 0.06 & 0.94 & 0.06 & $1 \cdot 18$ & 0.13 & 0.74 & 0.05 & 0.86 & 0.08 \\
\hline Oils (g) & 24.4 & 0.3 & 34.6 | & 0.7 & 27.9 & 0.5 & $40 \cdot 2 \pi$ & 1.3 & $21 \cdot 0$ & 0.3 & $29 \cdot 6$ ๆ & 0.7 \\
\hline Solid fats $(\mathrm{g})$ & $36 \cdot 6$ & 0.5 & 34.8 & $0 \cdot 8$ & 42.6 & 0.8 & 39.6 & 1.5 & $30 \cdot 6$ & 0.5 & $29 \cdot 8$ & 0.8 \\
\hline Added sugars (tsp-eq.) & 18.2 & 0.3 & $16 \cdot 9$ & 0.4 & 20.9 & 0.5 & $19 \cdot 4$ & 0.7 & $15 \cdot 4$ & 0.3 & 14.4 & 0.4 \\
\hline Alcoholic drinks (number) & 0.8 & $<0.1$ & 0.8 & $0 \cdot 1$ & 1.2 & 0.1 & $1 \cdot 1$ & 0.1 & 0.5 & $<0.1$ & 0.5 & 0.1 \\
\hline \multicolumn{13}{|l|}{ Percentage of total energy intake (\%) } \\
\hline Solid fats & $14 \cdot 8$ & $0 \cdot 1$ & $13.4 \pi$ & 0.3 & $14 \cdot 8$ & 0.2 & $13 \cdot 1 \rrbracket$ & 0.4 & $14 \cdot 7$ & 0.2 & $13 \cdot 6$ I & 0.3 \\
\hline Added sugars & 13.9 & 0.2 & $12.4 \rrbracket$ & 0.3 & 13.7 & 0.2 & $12 \cdot 3$ & 0.4 & 14.1 & 0.3 & 12.5 & 0.4 \\
\hline
\end{tabular}

c-eq., cup equivalents; oz-eq., ounce equivalents; tsp-eq., teaspoon equivalents.

*Estimates adjusted for sex (as applicable), race/ethnicity, age, income category and smoking status. Age was entered as a continuous variable.

tUSDA Food Patterns, including the Healthy US-Style Eating Pattern, are described in Appendix 3 of the Dietary Guidelines for Americans 2015-2020 (10) †Excludes pregnant and lactating females.

$\S$ Legumes (beans and peas) may be counted as either vegetables or protein foods. In this analysis, they are counted as vegetables.

Excludes cooked soyabeans and edamame, which are included in the legumes (beans and peas) component, and soya milk, which is included in dairy.

IWithin sex, adjusted estimate of food component total intake by salad reporters differs significantly from that of non-reporters $(P<0.001)$. 
Table 3 Healthy US-Style Eating Pattern* recommendations: percentage of individuals meetingt by salad reporting status and likelihood of meeting among salad reporters; US adults $\ddagger$ ( $n 9678$ ) aged $\geq 20$ years, What We Eat in America, National Health and Nutrition Examination Survey 2011-2014

\begin{tabular}{|c|c|c|c|c|c|c|}
\hline \multirow[b]{2}{*}{ USDA Food Pattern component } & \multicolumn{2}{|c|}{ Non-reporters } & \multicolumn{2}{|c|}{ Reporters } & \multirow[b]{2}{*}{$\mathrm{RR} \S$} & \multirow[b]{2}{*}{$99.9 \% \mathrm{Cl}$} \\
\hline & $\%$ & SE & $\%$ & $\mathrm{SE}$ & & \\
\hline Vegetables $\|$ & $10 \cdot 2$ & 0.5 & 33.7 & 1.8 & 3.32 & $2.54,4.33$ \\
\hline Dark green vegetables & $10 \cdot 3$ & 0.6 & 34.6 & 1.2 & 3.35 & $2 \cdot 70,4 \cdot 16$ \\
\hline Red \& orange vegetables & $10 \cdot 9$ & 0.5 & $23 \cdot 6$ & $1 . .4$ & $2 \cdot 17$ & $1 \cdot 69,2.79$ \\
\hline Legumes (beans \& peas) & $14 \cdot 3$ & 0.6 & $16 \cdot 4$ & 1.3 & $1 \cdot 14$ & $0.88,1.48$ \\
\hline Starchy vegetables & $19 \cdot 2$ & 0.8 & $16 \cdot 9$ & 1.2 & 0.88 & $0.69,1.11$ \\
\hline Other vegetables & 21.5 & 0.7 & 63.9 & 1.7 & $2 \cdot 97$ & $2.54,3.47$ \\
\hline Fruits & $16 \cdot 3$ & 0.7 & $19 \cdot 4$ & 1.7 & 1.19 & $0.82,1.72$ \\
\hline Grains & $38 \cdot 1$ & 0.6 & 34.9 & 1.5 & 0.92 & $0.78,1.08$ \\
\hline Whole grains & $5 \cdot 4$ & 0.5 & $5 \cdot 3$ & 0.7 & 0.98 & $0.63,1.53$ \\
\hline Refined grains & 33.0 & 0.7 & $41 \cdot 0$ & 1.5 & 1.24 & $1.08,1.43$ \\
\hline Whole $\geq$ refined & 8.2 & 0.5 & $12 \cdot 4$ & 1.0 & 1.52 & $1.12,2.07$ \\
\hline Dairy - n & $14 \cdot 3$ & 0.5 & $15 \cdot 1$ & 1.2 & 1.05 & $0.76,1.47$ \\
\hline Protein foods $\|$ & $40 \cdot 6$ & 0.7 & $48 \cdot 2$ & 1.5 & 1.19 & $1.07,1.32$ \\
\hline Seafood & $11 \cdot 3$ & 0.7 & $17 \cdot 2$ & 1.3 & 1.53 & $1.21,1.93$ \\
\hline Meats, poultry, eggs & $48 \cdot 6$ & $1 \cdot 1$ & $50 \cdot 7$ & $2 \cdot 2$ & 1.04 & $0.90,1.21$ \\
\hline Nuts, seeds, soya products ${ }^{\star *}$ & $24 \cdot 3$ & 0.9 & 28.9 & 1.6 & 1.19 & $0.95,1.48$ \\
\hline Oils & $29 \cdot 1$ & 0.8 & $49 \cdot 3$ & 1.6 & 1.69 & $1.45,1.97$ \\
\hline Solid fats & $29 \cdot 4$ & 0.9 & 33.4 & 1.7 & $1 \cdot 14$ & $0.94,1.37$ \\
\hline Added sugars & $42 \cdot 1$ & $1 \cdot 1$ & 47.4 & 1.7 & $1 \cdot 13$ & $0.96,1.32$ \\
\hline Alcoholic drinks & $81 \cdot 7$ & 0.8 & $79 \cdot 3$ & 1.8 & 0.97 & $0.89,1.06$ \\
\hline
\end{tabular}

$\mathrm{RR}$, risk ratio.

*USDA Food Patterns, including the Healthy US-Style Eating Pattern, are described in Appendix 3 of the Dietary Guidelines for Americans 2015-2020(10).

†Each individual's recommended energy level and corresponding recommended intakes were assigned based on sex, age and self-reported physical activity level. For most components, 'meeting' means consuming at least the recommended amount. However, for refined grains, solid fats, added sugars and alcoholic drinks, 'meeting' means not exceeding the recommended limit.

‡Excludes pregnant and lactating females.

$\S$ Salad non-reporters are the referent group $(R R=1.00)$. RR were obtained from average marginal predictions (adjusted prevalence estimates) in the fitted logistic model ${ }^{(40,41)}$. Prevalence estimates were adjusted for sex, age, race/ethnicity, income category and smoking status. Age was entered as a continuous variable.

\|Legumes (beans and peas) may be counted as either vegetables or protein foods. In this analysis, they are counted as vegetables.

IThe Dietary Guidelines for Americans 2015-2020 recommend that at least half of total grains intake should be whole grains ${ }^{(10)}$. ${ }^{\star *}$ Excludes cooked soyabeans and edamame, which are included in the legumes (beans and peas) component, and soya milk, which is included in dairy.

was very low, regardless of salad reporting status. Among salad non-reporters, the prevalence of meeting recommendations was less than $25 \%$ for all vegetable subgroups. Even among salad reporters, the percentage meeting recommendations exceeded $40 \%$ for only one vegetable subgroup: 'other' vegetables (63.9\%). Yet, in terms of risk ratios (RR), salad reporters were about three or more times as likely as non-reporters to meet their recommendations for total vegetables ( $\mathrm{RR}=3 \cdot 32 ; 99 \cdot 9 \% \mathrm{CI}$ $2 \cdot 54,4.33)$, dark green vegetables $(\mathrm{RR}=3.35$; $99.9 \%$ CI $2 \cdot 70,4 \cdot 16)$ and 'other' vegetables ( $R R=2.97$; 99.9\% CI $2.54,3.47$ ), and about twice as likely to meet their recommendation for red and orange vegetables $(\mathrm{RR}=$ 2.17; 99.9\% CI 1.69, 2.79).

Salad reporting status was also associated with the likelihood of meeting a few non-vegetable recommendations. Relative to non-reporters, salad reporters were more likely to meet their limit on intake of refined grains $(\mathrm{RR}=1.24 ; 99.9 \%$ CI 1.08, 1.43). Although extremely low percentages of both salad non-reporters and reporters $(5 \%$ of each) met their recommendations for whole grains, reporters were more likely to consume at least half their grains as whole grains ( $\mathrm{RR}=1.52 ; 99.9 \% \mathrm{CI} 1.12,2.07)$. Salad reporters were also significantly more likely to meet their recommendations for total protein foods $(\mathrm{RR}=1 \cdot 19$; $99.9 \%$ CI $1.07,1.32)$, seafood ( $R R=1.53 ; 99.9 \%$ CI 1.21 , $1.93)$ and oils $(\mathrm{RR}=1.69 ; 99.9 \%$ CI $1.45,1.97)$ than were salad non-reporters.

Findings by sex were nearly identical to those for the adult population as a whole (Table 4) for both vegetable and non-vegetable Food Pattern components. The only ways in which findings by sex did not mirror those for all adults together were that no differences in adherence to recommendations by salad reporting status were found among women for refined grains or among men for consuming half of all grains as whole grains or for total protein foods.

\section{Discussion}

The DGA recommend that consumers incorporate vegetable dishes such as salads into more meals and snacks in order to boost daily intake of vegetables ${ }^{(10)}$. The present 
Table 4 Healthy US-Style Eating Pattern* recommendations: percentage of individuals meetingt by salad reporting status and likelihood of meeting among salad reporters, by sex; US adults ( $n$ 9678) aged $\geq 20$ years, What We Eat in America, National Health and Nutrition Examination Survey 2011-2014

\begin{tabular}{|c|c|c|c|c|c|c|c|c|c|c|c|c|}
\hline \multirow[b]{3}{*}{ USDA Food Pattern component } & \multicolumn{6}{|c|}{ Males } & \multicolumn{6}{|c|}{ Females $\ddagger$} \\
\hline & \multicolumn{2}{|c|}{ Non-reporters } & \multicolumn{2}{|c|}{ Reporters } & \multirow[b]{2}{*}{$\mathrm{RR} \S$} & \multirow[b]{2}{*}{$99.9 \% \mathrm{Cl}$} & \multicolumn{2}{|c|}{ Non-reporters } & \multicolumn{2}{|c|}{ Reporters } & \multirow[b]{2}{*}{$\mathrm{RR} \S$} & \multirow[b]{2}{*}{$99.9 \% \mathrm{Cl}$} \\
\hline & $\%$ & SE & $\%$ & SE & & & $\%$ & SE & $\%$ & SE & & \\
\hline Vegetables $\|$ & $9 \cdot 7$ & 0.7 & 29.5 & $2 \cdot 1$ & 3.05 & $2 \cdot 19,4 \cdot 24$ & $10 \cdot 6$ & 0.9 & $37 \cdot 3$ & $2 \cdot 0$ & 3.51 & $2 \cdot 29,5 \cdot 38$ \\
\hline Dark green vegetables & $9 \cdot 2$ & 0.8 & 27.5 & $2 \cdot 1$ & 2.98 & $1.96,4.52$ & 11.4 & 0.7 & 40.7 & 1.8 & 3.58 & $2.74,4.68$ \\
\hline Red \& orange vegetables & $10 \cdot 9$ & 0.8 & $20 \cdot 6$ & $2 \cdot 0$ & 1.89 & $1.26,2.84$ & $10 \cdot 7$ & 0.8 & $26 \cdot 0$ & 1.6 & 2.42 & $1.72,3.39$ \\
\hline Legumes (beans \& peas) & $15 \cdot 9$ & 0.8 & $18 \cdot 3$ & $1 \cdot 8$ & $1 \cdot 15$ & $0.76,1.75$ & $12 \cdot 8$ & 0.7 & 14.7 & 1.7 & $1 \cdot 15$ & $0.77,1.71$ \\
\hline Starchy vegetables & $20 \cdot 0$ & 1.1 & $17 \cdot 0$ & 1.8 & 0.85 & $0.53,1.34$ & $18 \cdot 3$ & 0.9 & $16 \cdot 8$ & 1.7 & 0.91 & $0.63,1.32$ \\
\hline Other vegetables & $20 \cdot 7$ & 0.8 & 63.0 & 2.4 & 3.04 & $2.43,3.80$ & $22 \cdot 3$ & 1.0 & 64.5 & $2 \cdot 0$ & $2 \cdot 89$ & $2.41,3.47$ \\
\hline Fruits & 13.9 & 0.9 & 17.5 & $2 \cdot 0$ & 1.26 & $0.78,2.04$ & $18 \cdot 7$ & 1.2 & 21.4 & $2 \cdot 0$ & $1 \cdot 14$ & $0.72,1.81$ \\
\hline Grains & $36 \cdot 3$ & 1.0 & $31 \cdot 1$ & $2 \cdot 7$ & 0.86 & $0.61,1.21$ & 39.8 & 1.0 & 38.0 & $2 \cdot 1$ & 0.95 & $0.77,1.18$ \\
\hline Whole grains & $5 \cdot 0$ & 0.5 & $5 \cdot 6$ & $1 \cdot 0$ & $1 \cdot 12$ & $0.58,2.15$ & $5 \cdot 8$ & 0.6 & $5 \cdot 0$ & 0.7 & 0.86 & $0.47,1.58$ \\
\hline Refined grains & 32.4 & 1.0 & 43.3 & 2.6 & 1.34 & $1.02,1.75$ & 33.7 & 1.2 & 39.4 & 1.8 & 1.17 & $0.93,1.48$ \\
\hline Whole $\geq$ refined $\|$ & $7 \cdot 8$ & 0.6 & 12.5 & 1.7 & 1.59 & $0.95,2.67$ & 8.5 & 0.6 & $12 \cdot 4$ & 1.0 & 1.45 & $1.01,2.08$ \\
\hline Dairy & $19 \cdot 3$ & 0.8 & $19 \cdot 4$ & 1.6 & 1.00 & $0.70,1.44$ & 9.4 & 0.7 & $10 \cdot 7$ & 1.5 & $1 \cdot 14$ & $0.66,1.95$ \\
\hline Protein foods\| & $48 \cdot 6$ & 1.0 & $54 \cdot 6$ & $2 \cdot 7$ & $1 \cdot 12$ & $0.96,1.32$ & $32 \cdot 8$ & 1.1 & 41.3 & 1.9 & 1.26 & $1.05,1.50$ \\
\hline Seafood & $11 \cdot 3$ & 0.8 & $18 \cdot 0$ & $2 \cdot 1$ & 1.59 & $1.05,2.41$ & $11 \cdot 3$ & 0.9 & $16 \cdot 4$ & 1.5 & 1.46 & $1.10,1.93$ \\
\hline Meats, poultry, eggs & $57 \cdot 1$ & 1.2 & $56 \cdot 4$ & 3.0 & 0.99 & $0.84,1.17$ & $40 \cdot 1$ & 1.6 & 44.7 & 2.4 & 1.12 & $0.89,1.40$ \\
\hline Nuts, seeds, soya products** & $22 \cdot 7$ & $1 \cdot 2$ & $29 \cdot 4$ & $2 \cdot 0$ & $1 \cdot 29$ & $0.98,1.70$ & $25 \cdot 9$ & $1 \cdot 2$ & $28 \cdot 8$ & $2 \cdot 2$ & $1 \cdot 11$ & $0.79,1.56$ \\
\hline Oils & 28.6 & 1.0 & $50 \cdot 1$ & $2 \cdot 8$ & 1.75 & $1 \cdot 39,2 \cdot 21$ & $29 \cdot 7$ & $1 \cdot 1$ & 48.6 & $2 \cdot 0$ & 1.64 & $1.31,2.04$ \\
\hline Solid fats & 28.4 & 1.2 & 34.9 & $2 \cdot 7$ & 1.23 & $0.90,1.69$ & $30 \cdot 3$ & 1.0 & $32 \cdot 6$ & 1.8 & 1.08 & $0.87,1.33$ \\
\hline Added sugars & $42 \cdot 8$ & $1 \cdot 2$ & $49 \cdot 4$ & $2 \cdot 2$ & $1 \cdot 15$ & $0.98,1.36$ & 41.5 & $1 \cdot 7$ & $45 \cdot 7$ & $2 \cdot 1$ & $1 \cdot 10$ & $0.87,1.39$ \\
\hline Alcoholic drinks & $80 \cdot 7$ & 0.9 & $79 \cdot 3$ & $2 \cdot 2$ & 0.98 & $0.89,1.09$ & 82.6 & 1.2 & $80 \cdot 0$ & 1.8 & 0.97 & $0.88,1.06$ \\
\hline
\end{tabular}

RR, risk ratio.

*USDA Food Patterns, including the Healthy US-Style Eating Pattern, are described in Appendix 3 of the Dietary Guidelines for Americans 2015-2020(10). †Each individual's recommended energy level and corresponding recommended intakes were assigned based on sex, age and self-reported physical activity level. For most components, 'meeting' means consuming at least the recommended amount. However, for refined grains, solid fats, added sugars and alcoholic drinks, 'meeting' means not exceeding the recommended limit.

‡Excludes pregnant and lactating females.

$\S$ Salad non-reporters are the referent group $(R R=1.00)$. RR were obtained from average marginal predictions (adjusted prevalence estimates) in the fitted logistic model ${ }^{(40,41)}$. Prevalence estimates were adjusted for age, race/ethnicity, income category and smoking status. Age was entered as a continuous variable.

|l Legumes (beans and peas) may be counted as either vegetables or protein foods. In this analysis, they are counted as vegetables.

IThe Dietary Guidelines for Americans 2015-2020 recommend that at least half of total grains intake should be whole grains ${ }^{(10)}$.

${ }^{\star \star}$ Excludes cooked soyabeans and edamame, which are included in the legumes (beans and peas) component, and soya milk, which is included in dairy.

study is the first to confirm that, among adults in the USA, heeding this guidance is associated with greater adherence to national dietary recommendations.

In this large, nationally representative sample of US adults, salad reporters' higher intakes of total, dark green, red and orange, and 'other' vegetables translated into a two- to threefold greater likelihood of meeting the Healthy US-Style Eating Pattern recommendations for these Food Pattern components. More modest associations were seen between salad reporting and differences in intake and likelihood of meeting recommendations for other Food Pattern components. Salad reporters had higher intakes of and likelihood of meeting recommendations for protein foods, seafood and oils. They were also more likely to consume half their grains as whole grains, although this seems to have been mainly through being more likely to stay within their limit on refined grains rather than through consuming more whole grains. For the most part, findings when analysed by sex reflected those for the adult population as a whole.

Some of the observed differences, such as those for vegetables and oils, seem likely to be directly attributable to salad consumption. For example, it is noteworthy that salad's contribution to the total vegetables intake of salad reporters accounts for the difference in intake of total vegetables between salad reporters and non-reporters. The same pattern was seen for dark green, red and orange, and 'other' vegetables. This pattern suggests that those who eat salads are not consuming them in place of other vegetable dishes but rather in addition to them, in harmony with intent of the DGA suggestion. Salad reporters' higher intake of and greater adherence to recommendations for oils also seem directly attributable to salad consumption, since most salads are consumed with salad dressing. The vast majority of salad dressings reported in 2011-2014 contained some fat. Post hoc analyses showed that salads contributed $36 \cdot 0 \%$ of salad reporters' overall intake of oils, an amount that more than accounted for the difference in intake of oils between salad reporters and non-reporters.

It is possible that the observed differences for protein foods might also be attributable in some degree to salad ingredients. Previous research showed that $19 \%$ of salads consumed by individuals of all ages contained some meat, 
poultry or fish, and that, in salads containing those ingredients, they were present in an average amount of about $2 \cdot 4 \mathrm{oz}(60 \mathrm{~g})^{(20)}$.

Potential explanations for some other observed differences are more complicated and may have more to do with healthier food choices overall by salad reporters than with salad consumption per se. It is unlikely that salad reporters' lower intake of refined grains and higher prevalence of staying within the recommended limit on refined grains are due directly to salad consumption. Possibly linked to these findings is the fact that salad reporters obtained slightly lower percentages of their total energy intake from solid fats and added sugars, although no difference by salad reporting status was found in intake of either solid fat (in grams) or added sugars (in teaspoon equivalents) or in the likelihood of meeting the recommendation that each of those components provide less than $10 \%$ of total energy. Support for the idea that the findings for refined grains, solid fats and added sugars may be related is provided by the Dietary Guidelines Advisory Committee's finding that the food categories that accounted for over $90 \%$ of refined grains intake also accounted for $47 \%$ of saturated fats and $28 \%$ of added sugars ${ }^{(42)}$ (p. 45).

While much research has focused on intake of vegetables in general (and even more on fruits and vegetables in the aggregate), little research has analysed salads specifically. One notable exception is the study conducted by Su and $\operatorname{Arab}^{(19)}$, which used NHANES III dietary data collected in 1988-1994. In that study, salad consumption was defined in three different ways. Using the broadest of those definitions ('garden salad or raw vegetable consumption on the day of the assessment'), which was the closest to that of the present study, the authors found that $30-35 \%$ of adults in four sex-age groups consumed salad. The higher prevalence of salad consumption in that study may be due to the inclusion of some raw vegetables consumed alone that would have been excluded from the present study. Conversely, Su and Arab's finding regarding the use of salad dressing ( $<10 \%$ of salads) was much lower than ours (83\%). However, those authors recognised the implausibility of that finding, and it led them to question the validity of the salad dressing data in NHANES III. One reason for our higher estimate may be the presence of detailed questions about salad ingredients, including specific probes concerning the consumption of dressing on salads, in the USDA Automated Multiple-Pass Method used in collecting WWEIA, NHANES data. Therefore, in addition to being more timely, it is likely that our study provides a more accurate estimate of the prevalence of dressing being consumed on salad.

Concomitant with its associations with improved adherence to national recommendations, salad consumption has also been shown to be associated with biomarkers of nutritional status. Su and Arab ${ }^{(19)}$ analysed associations between salad consumption and blood indicators of several nutrients and bioactive components. In that study, positive associations with level of salad consumption were found for both serum and red-blood-cell folate and for serum vitamins A (men only), $\mathrm{C}$ and $\mathrm{E}, \alpha$ - and $\beta$-carotene, retinyl esters and lycopene. Such beneficial associations may be enhanced by the common co-consumption of salad dressing. Fats in salad dressing have been shown to aid in absorption of nutrients abundant in salad ingredients, including $\alpha_{-}^{(43,44)}$ and $\beta$-carotene ${ }^{(43,44)}$, retinyl palmitate $^{(44)}$, lutein ${ }^{(44)}$, lycopene ${ }^{(43,44)}$, phylloquinone ${ }^{(43)}$, and $\alpha$ - and total tocopherol ${ }^{(44)}$.

There are some limitations to the present study. First, salad reporting status was determined using only one day of dietary intake. It is unknown if those classified as salad reporters in the present study have usual intakes of food groups that differ from those of non-reporters. Evaluating adherence to recommendations for the vegetable and protein foods subgroups, which are in terms of servings per week, necessitated the unsubstantiated assumption that the daily intake is representative of the week as a whole. Second, possible overestimation of self-reported physical activity may have led to assignment of erroneously high energy levels and accompanying food group recommendations. Whereas approximately half of all adults in the present study reported $\geq 300$ min of activity per week, Troiano et al. ${ }^{(45)}$ analysed physical activity measured by accelerometer and found that $<5 \%$ of US adults in 2003-2004 obtained an average of $30 \mathrm{~min}$ of physical activity per day. Assignment of a higher-thanappropriate energy level would have understated the percentage of adults meeting recommendations for components to be encouraged, including vegetables, but would have inflated the percentage meeting recommendations for components to be limited, such as refined grains. Since it is unknown if overestimation of selfreported physical activity differed between reporters and non-reporters, its effect on the association between salad reporting status and meeting recommendations cannot be determined.

It was not possible to assess the Food Pattern component 'calories for other uses', since its definition includes 'added refined starches' which are not included in FPED. However, the present study did evaluate the two major contributors to 'calories for other uses', namely solid fats and added sugars, which have their own specific recommendations ( $10 \%$ of total energy intake from each). The total of those two recommendations $(<20 \%$ of total energy) exceeds the limit on 'calories for other uses' in all the energy levels assigned in the study, which ranges from 8 to $16 \%$ of total energy. Thus, an individual's intake could meet the recommended limits for both solid fats and added sugars yet still exceed the limit on 'calories for other uses', even without including other sources of this energy. Considering the low percentages of adults meeting their recommended limits for solid fats $(33 \%$ of salad reporters and $29 \%$ of non-reporters) and added sugars ( 47 and $42 \%$, 
respectively), it is likely that the percentage of adults staying within their recommended limit on "calories for other uses' is considerably lower.

It should be noted that it is not necessary for good health to eat salad or even raw vegetables. This is merely one strategy among many potential ways to increase the intake of vegetables overall. For some people, salad may be unavailable ${ }^{(46,47)}$, unaffordable $e^{(48,49)}$ or unchewable ${ }^{(50,51)}$. Other options, such as frozen and canned vegetables, are more affordable ${ }^{(48)}$ and are also rich in nutrients ${ }^{(48,52,53)}$. Moreover, cooking vegetables provides some protection against the risk of food-borne illness attributable to raw produce $-46 \%$ of food-borne illnesses reported in the USA from 1998 to $2008^{(54)}$. Therefore, the findings presented here do not imply that one must consume salad in order to improve adherence to the DGA. In fact, the Dietary Guidelines Advisory Committee detailed a wide range of strategies that not only consumers themselves but also agriculture, the food industry, food-service and retail establishments, government and other aspects of the food system can employ to promote healthier intakes $^{(10,42)}$.

\section{Conclusions}

Consuming salad is associated with higher intake of several components of the Healthy US-Style Eating Pattern, especially vegetables and oils, and consequently with greater adherence to the DGA recommendations outlined in that pattern. In addition, other beneficial shifts were seen, some likely due to the content of salads per se and others more likely due to a pattern of healthier food choices overall. Nevertheless, for most Food Pattern components, intakes and adherence to recommendations were low regardless of salad reporting status. Results of the present study confirm the DGA message that incorporating more salads into the diet is an effective strategy (among many possible strategies) to augment vegetable consumption and adherence to dietary recommendations concerning vegetables.

\section{Acknowledgements}

Financial support: This research received no specific grant from any funding agency in the public, commercial or notfor-profit sectors. Conflict of interest: None. Authorship: R.S.S. and M.K.H. formulated the research question; R.S.S. and C.W.E. designed the study; J.D.G., R.S.S. and M.K.H. prepared the data; J.D.G. conducted the statistical analyses; R.S.S. and C.W.E. prepared the manuscript; R.S.S. had final responsibility for its content; A.J.M. provided supervisory programmatic support. All authors read and approved the final manuscript. Ethics of human subject participation: Written informed consent was obtained from all participants. The survey protocol was approved by the US Department of Health and Human Services, Centers for Disease Control and Prevention, National Center for Health Statistics, Research Ethics Review Board. The current study was a secondary analysis and thus exempt from further review under Title 45 Code of Federal Regulations section 46.101(b).

\section{References}

1. Turati F, Rossi M, Pelucchi C et al. (2015) Fruit and vegetables and cancer risk: a review of southern European studies. Br J Nutr 113, Suppl. 2, S102-S110.

2. Link LB \& Potter JD (2004) Raw versus cooked vegetables and cancer risk. Cancer Epidemiol Biomarkers Prev 13, 1422-1435.

3. Sant M, Allemani C, Sieri S et al. (2007) Salad vegetables dietary pattern protects against HER-2-positive breast cancers: a prospective Italian study. Int J Cancer 121, 911-914.

4. Aune D, Giovannucci E, Boffetta P et al. (2017) Fruit and vegetable intake and the risk of cardiovascular disease, total cancer and all-cause mortality - a systematic review and dose-response meta-analysis of prospective studies. Int $J$ Epidemiol 46, 1029-1056.

5. von Ruesten A, Feller S, Bergmann MM et al. (2013) Diet and risk of chronic diseases: results from the first 8 years of follow-up in the EPIC-Potsdam study. Eur J Clin Nutr 67, 412-419.

6. Chan Q, Stamler J, Brown IJ et al:; INTERMAP Research Group (2014) Relation of raw and cooked vegetable consumption to blood pressure: the INTERMAP Study. J Hum Hypertens 28, 353-359.

7. Oude Griep LM, Verschuren WM, Kromhout D et al. (2011) Raw and processed fruit and vegetable consumption and 10 -year stroke incidence in a population-based cohort study in the Netherlands. Eur J Clin Nutr 65, 791-799.

8. Liu RH (2013) Health-promoting components of fruits and vegetables in the diet. Adv Nutr 4, issue 3, 384S-392S.

9. Davis C \& Saltos E (1999) Dietary recommendations and how they have changed over time. In America's Eating Habits: Changes and Consequences, pp. 33-50 [E Frazão, editor]. Washington, DC: US Department of Agriculture, Economic Research Service; available at https://www.ers. usda.gov/publications/pub-details/?pubid $=42243$

10. US Department of Health and Human Services \& US Department of Agriculture (2015) Dietary Guidelines for Americans 2015-2020, 8th ed. HHS Publication no. HHSODPHP-2015-2020-01-DGA-A; USDA Home and Garden Bulletin no. 232. http://health.gov/dietaryguidelines/2015/ guidelines/ (accessed March 2018).

11. Produce for Better Health Foundation (2008-2018) Fruit \& vegetable nutrition. https://www.fruitsandveggiesmorematt ers.org/fruit-veggie-nutrition (accessed January 2018).

12. US Department of Agriculture (2018) MyPlate. https://www. choosemyplate.gov/MyPlate (accessed January 2018).

13. US Department of Agriculture, SNAP-Ed Connection (2018) Fruits and vegetables. https://snaped.fns.usda.gov/nutritioneducation-materials/foods/fruits-and-vegetables (accessed January 2018).

14. US Department of Agriculture, Food and Nutrition Service (2018) Women, Infants, and Children (WIC Program) I Final rule: revisions in the WIC food packages. https://www.fns. usda.gov/wic/final-rule-revisions-wic-food-packages (accessed January 2018).

15. US Department of Agriculture, Food and Nutrition Service (2012) Nutrition Standards in the National School Lunch and School Breakfast Programs; Final rule, 7 CFR parts 210 
and 220. Fed Regist 77, 4088-4167; available at https:// www.gpo.gov/fdsys/pkg/FR-2012-01-26/pdf/2012-1010.pdf

16. US Department of Agriculture, Food and Nutrition Service (2018) Fresh Fruit and Vegetable Program. https://www.fns. usda.gov/ffvp/fresh-fruit-and-vegetable-program (accessed January 2018).

17. US Department of Agriculture, Food and Nutrition Service (2017) Senior Farmers' Market Nutrition Program. https:// www.fns.usda.gov/sfmnp/overview (accessed January 2018).

18. National Cancer Institute, Epidemiology and Genomics Research Program (2015) Usual dietary intakes: food intakes, US population, 2007-10. http://epi.grants.cancer. gov/diet/usualintakes/pop/2007-10/index.html （accessed January 2018).

19. Su LJ \& Arab L (2006) Salad and raw vegetable consumption and nutritional status in the adult US population: results from the Third National Health and Nutrition Examination Survey. J Am Diet Assoc 106, 1394-1404.

20. Sebastian RS, Wilkinson Enns C, Goldman JD et al. (2018) Salad Consumption in the US: What We Eat in America, NHANES 2011-2014. Dietary Data Brief no. 19. Beltsville, MD: US Department of Agriculture, Food Surveys Research Group; available at https://www.ars.usda.gov/ARSUserFiles/ 80400530/pdf/DBrief/19_Salad_consumption_2011_2014. pdf

21. Centers for Disease Control and Prevention, National Center for Health Statistics (2018) National Health and Nutrition Examination Survey I Questionnaires, datasets, and related documentation I Continuous NHANES. https://wwwn.cdc. gov/nchs/nhanes/continuousnhanes/default.aspx (accessed January 2018).

22. Johnson CL, Dohrmann SM, Burt VL et al. (2014) National Health and Nutrition Examination Survey: Sample Design, 2011-2014. Vital and Health Statistics Series 2, no. 162. Hyattsville, MD: US Department of Health and Human Services, Centers for Disease Control and Prevention, National Center for Health Statistics; available at https:// www.cdc.gov/nchs/data/series/sr_02/sr02_162.pdf

23. Centers for Disease Control and Prevention, National Center for Health Statistics (2018) National Health and Nutrition Examination Survey I Questionnaires, datasets, and related documentation I Response rates. https://wwwn.cdc.gov/ nchs/nhanes/ResponseRates.aspx (accessed January 2018).

24. Raper N, Perloff B, Ingwersen L et al. (2004) An overview of USDA's dietary intake data system. J Food Compost Anal 17, 545-555.

25. Moshfegh AJ, Rhodes DG, Baer DJ et al. (2008) The US Department of Agriculture Automated Multiple-Pass Method reduces bias in the collection of energy intakes. Am J Clin Nutr 88, 324-332.

26. Centers for Disease Control and Prevention, National Center for Health Statistics (2018) National Health and Nutrition Examination Survey I Questionnaires, datasets, and related documentation I NHANES 2013-2014. https://wwwn.cdc. gov/nchs/nhanes/ContinuousNhanes/Default.aspx?Begin Year=2013 (accessed January 2018).

27. Centers for Disease Control and Prevention, National Center for Health Statistics (2018) National Health and Nutrition Examination Survey I Questionnaires, datasets, and related documentation I NHANES 2011-2012. https://wwwn.cdc. gov/nchs/nhanes/ContinuousNhanes/Default.aspx?Begin Year=2011 (accessed January 2018).

28. Centers for Disease Control and Prevention, National Center for Health Statistics (2016) National Health and Nutrition Examination Survey | 2013-2014 Data documentation, codebook, and frequencies I Dietary interview technical support file - food codes (DRXFCD_H). https://wwwn.cdc. gov/Nchs/Nhanes/2013-2014/DRXFCD_H.htm （accessed January 2018).
29. Centers for Disease Control and Prevention, National Center for Health Statistics (2014) National Health and Nutrition Examination Survey I 2011-2012 Data documentation, codebook, and frequencies I Dietary interview technical support file - food codes (DRXFCD_G). https://wwwn.cdc. gov/Nchs/Nhanes/2011-2012/DRXFCD_G.htm (accessed January 2018).

30. US Department of Agriculture, Food Surveys Research Group (2017) Food Patterns Equivalents Database (FPED) overview. https://www.ars.usda.gov/northeast-area/belts ville-md-bhnrc/beltsville-human-nutrition-research-center/ food-surveys-research-group/docs/fped-overview/ (accessed January 2018).

31. Bowman SA, Clemens JC, Friday JE et al. (2017) Food Patterns Equivalents Database 2013-14: Methodology and User Guide. Beltsville, MD: US Department of Agriculture, Food Surveys Research Group; available at https://www. ars.usda.gov/ARSUserFiles/80400530/pdf/fped/FPED_1314. pdf

32. Bowman SA, Clemens JC, Friday JE et al. (2014) Food Patterns Equivalents Database 2011-12: Methodology and User Guide. Beltsville, MD: US Department of Agriculture, Food Surveys Research Group; available at https://www. ars.usda.gov/ARSUserFiles/80400530/pdf/fped/FPED_1112. pdf

33. US Department of Agriculture, Food Surveys Research Group (2017) Food Patterns Equivalents Database (FPED) database I Databases and SAS data sets. https://www.ars. usda.gov/northeast-area/beltsville-md-bhnrc/beltsville-humannutrition-research-center/food-surveys-research-group/docs/ fped-databases/ (accessed January 2018).

34. Centers for Disease Control and Prevention, National Center for Health Statistics (2015) National Health and Nutrition Examination Survey I 2013-2014 Data documentation, codebook, and frequencies I Physical activity (PAQ_H) [first published October 2015; last revised March 2017]. https://wwwn.cdc.gov/Nchs/Nhanes/2013-2014/PAQ_H.htm (accessed March 2018).

35. Centers for Disease Control and Prevention, National Center for Health Statistics (2015) National Health and Nutrition Examination Survey I 2011-2012 Data documentation, codebook, and frequencies I Physical activity (PAQ_G) [first published September 2013; last revised March 2017]. https://wwwn.cdc.gov/Nchs/Nhanes/2011-2012/PAQ_G.htm (accessed March 2018).

36. US Department of Health and Human Services (2008) Appendix 1. Translating scientific evidence about total amount and intensity of physical activity into guidelines. In 2008 Physical Activity Guidelines for Americans. ODPHP Publication no. U0036. Rockville, MD: US Department of Health and Human Services, Office of Disease Prevention and Health Promotion; available at https://health.gov/ paguidelines/pdf/paguide.pdf

37. Research Triangle Institute (2012) SUDAAN Language Manual, Volumes 1 and 2, Release 11. Research Triangle Park, NC: Research Triangle Institute.

38. Centers for Disease Control and Prevention, National Center for Health Statistics (2013) NHANES dietary web tutorial I Overview of NHANES survey design and weights. https:// www.cdc.gov/nchs/tutorials/Dietary/SurveyOrientation/Survey Design/intro.htm (accessed February 2018).

39. US Department of Health and Human Services, Office of the Assistant Secretary for Planning and Evaluation (2018) Poverty guidelines. https://aspe.hhs.gov/poverty-guidelines (accessed March 2018).

40. Graubard BI \& Korn EL (1999) Predictive margins with survey data. Biometrics 55, 652-659.

41. Bieler GS, Brown GG, Williams RL et al. (2010) Estimating model-adjusted risks, risk differences, and risk ratios from complex survey data. Am J Epidemiol 171, 618-623. 
42. Dietary Guidelines Advisory Committee (2015) Scientific Report of the 2015 Dietary Guidelines Advisory Committee. Washington, DC: US Department of Agriculture and US Department of Health and Human Services; available at https://health.gov/dietaryguidelines/2015-scientific-report/

43. Brown MJ, Ferruzzi MG, Nguyen ML et al. (2004) Carotenoid bioavailability is higher from salads ingested with full-fat than with fat-reduced salad dressings as measured with electrochemical detection. Am J Clin Nutr $\mathbf{8 0}$, 396-403.

44. White WS, Zhou Y, Crane A et al. (2017) Modeling the dose effects of soybean oil in salad dressing on carotenoid and fat-soluble vitamin bioavailability in salad vegetables. $\mathrm{Am} \mathrm{J}$ Clin Nutr 106, 1041-1051.

45. Troiano RP, Berrigan D, Dodd KW et al. (2008) Physical activity in the United States measured by accelerometer. Med Sci Sports Exerc 40, 181-188.

46. O'Malley J (2018) Finding produce in Alaska's long winter takes wiles and luck. New York Times. https://www.nyti.ms/ 2C98zEd (accessed March 2018).

47. Laska MN, Borradaile KE, Tester J et al. (2010) Healthy food availability in small urban food stores: a comparison of four US cities. Public Health Nutr 13, 1031-1035.

48. Drewnowski A \& Rehm CD (2013) Vegetable cost metrics show that potatoes and beans provide most nutrients per penny. PLoS One 8, e63277.
49. Cassady D, Jetter KM \& Culp J (2007) Is price a barrier to eating more fruits and vegetables for low-income families? $J$ Am Diet Assoc 107, 1909-1915.

50. Brennan DS, Singh KA, Liu P et al. (2010) Fruit and vegetable consumption among older adults by tooth loss and socio-economic status. Aust Dent J 55, 143-149.

51. Quandt SA, Chen H, Bell RA et al. (2010) Food avoidance and food modification practices of older rural adults: association with oral health status and implications for service provision. Gerontologist 50, 100-111.

52. Bouzari A, Holstege D \& Barrett DM (2015) Vitamin retention in eight fruits and vegetables: a comparison of refrigerated and frozen storage. J Agric Food Chem 63, 957-962.

53. Freedman MR \& Fulgoni VL 3rd (2016) Canned vegetable and fruit consumption is associated with changes in nutrient intake and higher diet quality in children and adults: National Health and Nutrition Examination Survey 2001-2010. J Acad Nutr Diet 116, 940-948.

54. Painter JA, Hoekstra RM, Ayers T et al. (2013) Attribution of foodborne illnesses, hospitalizations, and deaths to food commodities by using outbreak data, United States, 1998-2008. Emerg Infect Dis 19, 407-415.

55. National Institutes of Health, National Heart, Lung, and Blood Institute (2018) Classification of overweight and obesity by BMI, waist circumference, and associated disease risks. https://www.nhlbi.nih.gov/health/educational/lose_ wt/BMI/bmi_dis.htm (accessed March 2018). 